\title{
Islam, Sectarianism and Politics in Sudan since the Mahdiyya
}

Hurst \& Company, Londres, 2003, 252 p.

\section{Claude Arditi}

\section{(2) OpenEdition}

Édition électronique

URL : http://journals.openedition.org/assr/2463

DOI : $10.4000 /$ assr.2463

ISSN : $1777-5825$

\section{Éditeur}

Éditions de l'EHESS

Édition imprimée

Date de publication : 1 avril 2005

Pagination : 113-202

ISBN : 2-7132-2044-0

ISSN : 0335-5985

\section{Référence électronique}

Claude Arditi, «Islam, Sectarianism and Politics in Sudan since the Mahdiyya », Archives de sciences sociales des religions [En ligne], 130 | avril - juin 2005, document 130.53, mis en ligne le 02 décembre 2005, consulté le 21 septembre 2020. URL : http://journals.openedition.org/assr/2463 ; DOI : https:// doi.org/10.4000/assr.2463

Ce document a été généré automatiquement le 21 septembre 2020.

(c) Archives de sciences sociales des religions 


\section{Islam, Sectarianism and Politics in Sudan since the Mahdiyya}

Hurst \& Company, Londres, 2003, 252 p.

\section{Claude Arditi}

1 Cet ouvrage est précédé de plusieurs autres que l'auteur a consacrés à l'islam et à la politique au Soudan et en Égypte. Celui-ci qui condense les résultats de trente ans de recherches est consacré à une situation très particulière qui est celle du mouvement de la Mahdiyya au XIX ${ }^{e}$ siècle. Elle constitue un cas unique d'État islamique ayant réussi à expulser les occupants étrangers et à connaître des succès avant que les intérêts de l'impérialisme britannique ne parviennent à le détruire. En 1898 le consul général britannique du Caire élabora "un condominium agreement» qui réglementait les conditions dans lesquelles le Soudan anglo-égyptien devait être administré. Les dirigeants turco-égyptiens qui avaient gouverné le Soudan auparavant avaient été battus par un mouvement politique musulman et avaient dû quitter le pays dans les années 1880. Un État islamique avait été instauré. Il paraît normal dans ces conditions que le pouvoir colonial qui dirigeait le Soudan ait voulu extirper l'islam de la vie politique ou pour utiliser une terminologie occidentale séparer l'Église et l'État. Si les musulmans furent autorisés à pratiquer leur religion et à établir une justice fondée sur la shari'a dont les tribunaux traitaient les affaires relevant de la sphère privée, un gouvernement séculier composé d'administrateurs anglais aidés de quelques Égyptiens exerça le pouvoir politique. Il était prévu, sans autre précision, qu'une démocratie de type britannique soit progressivement instaurée dans le pays ainsi que dans les autres pays africains sous influence anglaise. Ce scénario ne s'est pas produit et l'auteur se demande si cet échec doit être imputé au colonisateur ou au fait que l'idée de séparer religion et politique est, dans le monde musulman, une contradiction dans les termes. En réalité l'auteur pense que les musulmans n'étaient pas désireux ou pas encore prêts à accepter la démocratie propagée par les colonisateurs.

2 C'est ce thème qui constitue le sujet principal de l'ouvrage et bien que ne soit étudié ici que le Soudan, cette question se pose aussi dans l'ensemble du monde musulman. L'auteur a déjà approfondi ce thème dans d'autres ouvrages. Il se limite ici à analyser le 
rôle de l'islam dans la vie politique du Soudan depuis la Mahdiyya jusqu'à l'indépendance en 1956. Il remarque que l'étude du Soudan depuis l'indépendance s'avère beaucoup plus problématique que l'étude de la période du coup d'État islamiste, perpétré par des militaires en 1989. Dans un dernier chapitre intitulé «Islam et démocratie » l'auteur examine les travaux qui ont été consacrés à cette question.

Dans les sociétés qui sont profondément marquées par des divisions religieuses, culturelles, linguistiques etc., la flexibilité nécessaire à l'émergence d'une démocratie est absente, remarque A. Lijphart, (Democraties: Patterns of Majoritarian and Consensus Government in Twenty-one Countries, Londres,Yale University Press, 1984). D'autres auteurs tels que J. Esposito et J. Voll (Islam and Democracy, Oxford, Oxford University Press, 1983) adoptent des points de vue contraires et soutiennent que les mouvements religieux de la fin $\mathrm{du} \mathrm{xx}^{\mathrm{e}}$ siècle ont favorisé la formation de systèmes politiques plus démocratiques. Bien que les travaux de ces auteurs ne soient, ni consacrés au Soudan, ni à la diversité culturelle, Warburg les trouve pertinents pour comprendre les pays multireligieux. Si une majorité impose ses convictions religieuses à une minorité, eston toujours en démocratie, se demande t-il ? Le statut de ahl al-dhimmah qui est proposé aux non-musulmans dans un État islamique est-il démocratique? Le nationalisme ethnique, fondé sur l'idéal de l'arabité, qui a dominé la vie politique du Soudan depuis l'indépendance conduit-il à la coexistence avec les autres religions dans un contexte démocratique? Telles sont les principales questions que se pose Warburg. Pour Esposito et Voll il n'y pas d'opposition de principe entre islam et démocratie mais le problème réside plutôt dans les différentes manières dont ces deux entités sont reliées l'une à l'autre. En conclusion, Warburg évoque les opinions d'observateurs soudanais sur ces questions. Pour Muhammad Ibrahim Khalil, qui enseigne le droit musulman, l'échec de la démocratie est à mettre en relation avec le faible niveau d'éducation. Mais ce dernier ne constitue pas un obstacle insurmontable. Pour cet auteur seuls les fondamentalistes pensent que islam et démocratie sont incompatibles. Il ajoute qu'une lecture attentive du Coran montre qu'une démocratie et un gouvernement constitutionnel ne sont nullement en contradiction avec l'esprit du livre saint et qu'une constitution laïque peut en être extraite.

Si un État basé sur l'islam peut être démocratique, pourquoi a-t-on connu autant d'échecs au Soudan et ailleurs, se demande alors Warburg. Mohamed Ahmed Mahgoub, premier Ministre dans les années 1960, répond (Democracy on Tria: Reflections on Arab and Africa Politics, Londres, Deutsch, 1974) que le démocratie a échoué dans toute l'Afrique et pas seulement au Soudan. Les raisons doivent en être cherchées, selon lui, dans l'incapacité des politiciens à formuler des politiques cohérentes, dans des rivalités de personnes et dans la recherche du profit à court terme. Pourtant le cas du Soudan présente deux particularités : d'une part sa première expérience historique de l'État est intervenue dans le cadre d'un État islamique et de l'autre les confréries, conséquence du néo-mahdisme, ont joué un rôle de premier plan aussi bien à l'époque coloniale qu'après l'indépendance. En conséquence, de nombreux auteurs soudanais et occidentaux attribuent l'échec de la démocratie aux confréries plutôt qu'à l'islam.

B. Lewis, quant à lui, reconnaît avec une certaine tristesse que la tolérance pratiquée par l'islam traditionnel n'existe plus et que les minorités non-musulmanes ont de nos jours moins de droits que dans le passé. Considérant qu'il n'existe pas de contradiction entre islam et démocratie, il pense que la doctrine islamique est autocratique mais non dictatoriale et que ses dirigeants ne sont pas au-dessus des lois. 


\section{AUTEUR}

CLAUDE ARDITI

Gabriel Warburg 